\section{Pre- and postoperative growth in persistent ductus arteriosus}

Growth retardation associated with congenital heart disease and the effect of cardiac surgery on it was the original subject of our study. We chose persistent ductus arteriosus as our model because the haemodynamic situation is normal in utero and ligation restores normal haemodynamics without a cardiotomy. We wished to find out what proportion of children failed to gain weight postoperatively, and whether we could identify these before the operation.

\section{Patients and methods}

We studied the cases of 110 otherwise healthy children who had had an uncomplicated persistent ductus arteriosus ligated at the Hospital for Sick Children, Toronto, between, January 1957 and December 1972. Those with a history of maternal rubella in pregnancy and those with chromosomal defects were excluded. We selected children who had been operated on under the age of 6 months, as they were the most severely affected and they had had their operation during the period when growth potential is greatest. The gestational age and birthweight, expressed in standard deviations, were available in 29 children. In only 24 of these were the operation and follow-up weights, expressed in centiles, available.

\section{Results}

The results are shown in the Fig., where the lines, taking birthweight as zero, show changes in weight centiles in the 24 children who had had their persistent ductus arteriosus ligated. By the time of operation $5(21 \%)$ had gained on their birthweight, $2(8 \%)$ had remained stationary, and $17(71 \%)$ had lost. Postoperatively 20 children (84\%) gained, $2(8 \%)$ remained stationary, and 2 fell. The 2 children who continued postoperatively their already downward trend were large-for-dates infants. The 2 who remained static were small-for-dates infants who had fallen away from the mean at the time of operation but remained on the same centile postoperatively.

The weight charts for the entire group of 24 children show that the small-for-dates children who failed to gain weight were part of a group of 7 children who were more than 2 SDs below the mean at the time of birth. This seemed a large proportion out of the total, so we compared the mean birthweights at 40 weeks' gestation with those from the population sample of Butler and Alberman (1969).

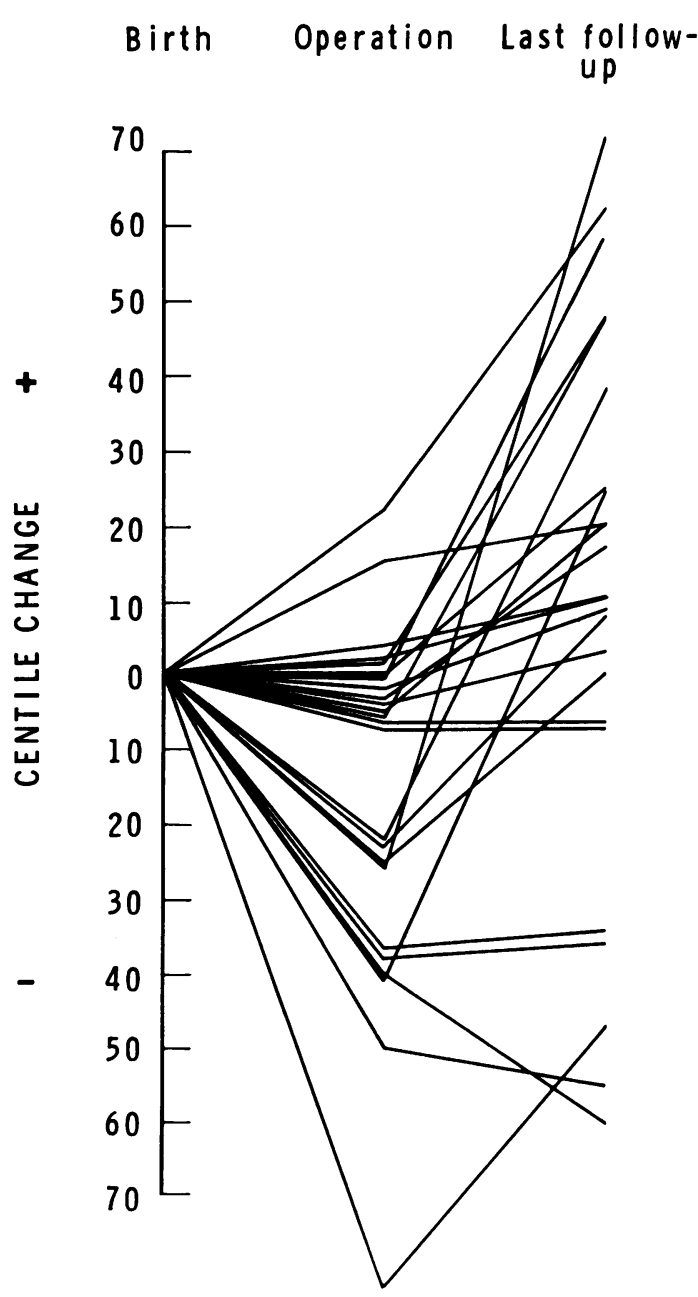

FIG.-Changes in weight centiles before and after operation in 25 children who had had their persistent ductus arteriosus ligated before 6 months of age. Zero = birthweight. 
TABLE

Mean birthweight at 40 weeks' gestation of infants with persistent ductus arteriosus requiring early surgery compared with mean birthweight at 40 weeks' gestation of normal infants (Butler and Alberman, 1969)

\begin{tabular}{|c|c|c|c|c|}
\hline & \multirow[b]{2}{*}{ No. } & \multicolumn{2}{|c|}{ Birthweight (kg) } & \multirow{2}{*}{$\begin{array}{c}\text { Significance of } \\
\text { difference } \\
\text { (Student's ' } t \text { ' test) }\end{array}$} \\
\hline & & Mean & SD & \\
\hline $\begin{array}{l}\text { Boys } \\
\text { Persistent ductus } \\
\text { Normal } \\
\text { Girls } \\
\text { Persistent ductus } \\
\text { Normal }\end{array}$ & $\begin{array}{r}6 \\
2035 \\
11 \\
1969\end{array}$ & $\begin{array}{l}3 \cdot 10 \\
3 \cdot 50 \\
\\
2 \cdot 87 \\
3 \cdot 34\end{array}$ & $\begin{array}{l}0.64 \\
0.46 \\
0.58 \\
0.44\end{array}$ & $\begin{array}{l}P<0.05 \\
P<0.001\end{array}$ \\
\hline
\end{tabular}

The birthweights of the infants with persistent ductus arteriosus were significantly lower than normal (Table). The boys with a ductus had a mean birthweight of $3.1 \mathrm{~kg}$ compared with a normal of $3.5 \mathrm{~kg}(\mathrm{P}<0.00)$, and the girls with a ductus had a mean birthweight of $2.87 \mathrm{~kg}$ compared with 3.34 $\mathrm{kg}$ in the normal $(\mathrm{P}<0.001)$.

\section{Discussion}

The birthweight of children with transposition of the great arteries is higher than normal. Campbell (1965) found normal birthweights with atrial septal defect and pulmonary stenosis but low birthweights in girls with coarctation and boys with ventricular septal defect. Engle (1954), reviewing 16 children who died with ventricular septal defects in infancy, noted that 14 of them had birthweights of less than $2.5 \mathrm{~kg}$ despite the fact that, with one exception, the pregnancies went to term. It is interesting that in 8 out of 9 children who came to necropsy the small muscular pulmonary arterioles had retained their 'fetal character'. Catherine Neill (1968) commented that low birthweight with congenital heart disease is unlikely to be due to the cardiac malformation but rather to other factors. Our observation that children with persistent ductus arteriosus tended to have a low birthweight-at the time when their haemodynamic status is normal-supports this contention.

However, at this stage we cannot say whether the low birthweight is due to some factor which both retards intrauterine growth and causes persistent ductus arteriosus, or that children who are smallfor-dates tend to have a persistent ductus arteriosus.

\section{Summary}

Children with a persistent ductus arteriosus requiring ligation under 6 months of age show evidence of intrauterine growth retardation. By the time of operation the weight centile of $17(71 \%)$ of 24 such infants had fallen, but 20 ( $84 \%$ ) of the 24 gained weight postoperatively. Those who did not do so were either large-for-dates infants growing towards the normal or small-for-dates infants who remained small postoperatively.

We thank Professor J. D. Keith for access to his records, and the United Oxford Hospitals for financing D. P.'s visit to Toronto in 1973.

\section{REFERENCFS}

Butler, N. R., and Alberman, E. D. (1969). Perinatal Problems. Second Report of the British Perinatal Mortality Survey. Livingstone, Edinburgh.

Campbell, M. (1965). Causes of malformation of the heart. British Medical fournal, 2, 895.

Engle, M. A. (1954). Ventricular septal defect in infancy. Pediatrics, 14, 16.

Neill, C. A. (1968). Etiologic and hemodynamic factors in congenital heart disease. Human Growth. Ed. by D. B. Cheek, p. 84. Lea and Febiger, Philadelphia.

Douglas Pickering, * Vera Rose, and Bruce ARMSTRONG

Radcliffe Infirmary, Oxford, and the Hospital for Sick Children, Toronto, Canada.

*Correspondence to Dr. D. Pickering, Paediatric Dept., Radcliffe Infirmary, Oxford OX2 6HE.

\section{Is cystic fibrosis an acid mucopolysaccharidosis?}

Myocardial fibrosis as a complication of cystic fibrosis (CF) has been described (Barnes, Gwynne, and Watt, 1970; McGiven, 1962; Mosquera and Becu, 1965; Nezelof and Lancret, 1959; Powell, Newman, and Hooker, 1957) but its cause is unknown. We here describe a case of CF where acid mucopolysaccharide deposits were present in the myocardium. 